\title{
The Impact of a Concussion-U Educational Program on Knowledge of and Attitudes about Concussion
}

\author{
Matthew E. Eagles, David J. Bradbury-Squires, Maria F. Powell, Justin R. Murphy, \\ Graeme D. Campbell, Falah B. Maroun
}

\begin{abstract}
Background: The diagnosis of a sports-related concussion is often dependent on the athlete self-reporting their symptoms. It has been suggested that improving youth athlete knowledge and attitudes toward concussion may increase self-reporting behaviour. The objective of this study was to determine if a novel Concussion-U educational program improves knowledge of and attitudes about concussion among a cohort of elite male Bantam and Midget AAA hockey players. Methods: Fifty-seven male Bantam and Midget AAA-level hockey players (mean age $=14.52 \pm 1.13$ years) were recruited from the local community. Each participant completed a modified version of the Rosenbaum Concussion Knowledge and Attitudes Survey-Student Version immediately before and after a Concussion-U educational presentation. Follow-up sessions were arranged 4 to 6 months after the presentation, and assessed retention of knowledge and attitude changes. Results: Forty-three players completed all three surveys. Concussion knowledge and attitude scores significantly $(p<0.01)$ increased from pre- to post-presentation by 12.79 and $8.41 \%$, respectively. At long-term follow-up, knowledge levels remained significantly $(p<0.01)$ higher than baseline by $8.49 \%$. Mean attitude scores were also increased at follow-up; however, this increase was not statistically significant. Conclusions: A Concussion-U educational program led to an immediate improvement in concussion knowledge and attitudes among elite male Bantam and Midget AAA hockey players. Increased knowledge was maintained at long-term follow-up, but improved attitude was not. Future studies should investigate whether similar educational programs influence symptom reporting and concussion incidence. In addition, they should focus on how to maintain improved concussion attitudes.
\end{abstract}

RÉSUMÉ: L'impact d'un programme éducatif Concussion- $U$ sur les connaissances et les attitudes concernant la commotion cérébrale. Contexte : Le diagnostic d'une commotion cérébrale subie dans le cadre d'activités sportives dépend souvent de l'autodéclaration des symptômes par l'athlète. D'aucuns suggèrent que le fait d'améliorer les connaissances et les attitudes des jeunes athlètes concernant la commotion cérébrale pourrait augmenter l'autodéclaration. Le but de cette étude était de déterminer si un nouveau programme éducatif, Concussion-U, améliore les connaissances et les attitudes concernant la commotion cérébrale chez une cohorte de joueurs de hockey élites masculins de niveau bantam et midget AAA. Méthodologie : Cinquantesept joueurs de hockey masculins de niveau bantam et midget AAA (âge moyen 14,52 $\pm 1,13$ ans) ont été recrutés dans la population locale. Chaque participant a complété une version modifiée pour étudiant du questionnaire Rosenbaum Concussion Knowledge and Attitudes Survey, immédiatement avant et après une présentation du programme éducatif Concussion-U. Des séances de suivi ont été cédulées entre 4 et 6 mois après la présentation afin d'évaluer le maintien des connaissances et les changements d'attitudes. Résultats : Quarante-trois joueurs ont complété les trois questionnaires. Les scores concernant les connaissances et les attitudes sur la commotion cérébrale ont augmenté de façon significative $(\mathrm{p}<0,01)$ après la présentation par rapport à ceux notés avant la présentation, soit de 12,79 et $8,41 \%$ respectivement. Au moment du suivi à long terme, les niveaux de connaissances sont demeurés significativement $(\mathrm{p}<0,01)$ plus élevés que ceux notés initialement, soit de $8,49 \%$. Les scores moyens concernant les attitudes étaient également augmentés au moment du suivi. Cependant, cette augmentation n'était pas significative au point de vue statistique. Conclusions : Un programme éducatif tel le programme Concussion-U a donné lieu à une amélioration immédiate des connaissances et des attitudes concernant la commotion cérébrale chez les joueurs de hockey élites masculins de niveau bantam et midget AAA. L'augmentation des connaissances était maintenue au moment du suivi à long terme mais l'amélioration des attitudes ne l'était pas. Des études ultérieures devraient examiner si des programmes éducatifs similaires influencent la déclaration des symptômes ainsi que l'incidence des commotions cérébrales et devraient cibler en particulier comment maintenir de meilleures attitudes concernant la commotion cérébrale.

Keywords: Concussion, Sports injuries, Education, Head trauma, Brain injury, Traumatic doi:10.1017/cjn.2016.263

Can J Neurol Sci. 2016; 43: 659-664

\footnotetext{
From the Department of Neurosurgery, Faculty of Medicine, Memorial University of Newfoundland, St. John's Newfoundland, Canada.

Received November 26, 2015. Final Revisions Submitted April 2, 2016. Date of Acceptance May 6, 2016.

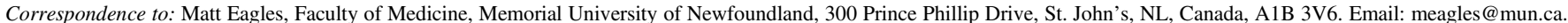




\section{INTRODUCTION}

The need for improved youth athlete education on sports-related concussion has been re-emphasized in Canada due to the death of a 17-year-old rugby player, Rowan Stringer, from second-impact syndrome, a rare but potentially fatal consequence of repeated concussions. $^{1,2}$ A coroner's inquest into her death recommended that concussion education be provided to all athletes, parents and coaches involved in youth sport. ${ }^{3}$ Furthermore, a great deal of media attention focuses on the suspected link between repetitive brain injuries and long-term cognitive, physical and behavioural disability. ${ }^{4-6}$ This is of particular relevance to ice hockey, which has one of the highest rates of concussion per athletic exposure. ${ }^{7,8}$

The diagnosis of concussion is highly dependent on an athlete's description of his/her symptoms. ${ }^{9,10}$ Consequently, an athlete's willingness to report their concussion symptoms is essential for proper management and recovery. It has been postulated that improving concussion knowledge will enable athletes to better recognize and respond to the symptoms of this injury. ${ }^{11,12}$ However, a recent study from Kroshus and colleagues $(2015)^{13}$ found that intention to report concussion symptoms (which depends in part on the athlete's attitudes about concussion) was a better predictor of athlete behaviour than their knowledge level. Thus, behavioural models such as the theory of planned behaviour (TPB) and the integrated behaviour model (IBM) are now being used to predict concussion symptom reporting behaviour in athletes. ${ }^{13,14}$

In their review, Caron et al. (2015) ${ }^{15}$ suggested that there is a need for education programs focused on improving long-term concussion knowledge, attitudes and behaviour in athletes. The education program utilized in the present study was developed and delivered by Concussion-U, a student-led interest group at Memorial University of Newfoundland (St. John's, Newfoundland). It was designed using materials from Parachute Canada under the guidance of the local ThinkFirst chapter director, Dr. Falah Maroun. The goal of the program was to expand upon the high-quality concussion resources from Parachute Canada by having medical students and a former hockey player deliver the information. It was hypothesized that this would better engage young athletes and lead to long-term improvement in concussion knowledge and attitudes.

The objective of our study was to determine if a novel Concussion-U educational program improved the knowledge of and attitudes about concussion among a cohort of elite male Bantam and Midget AAA hockey players.

\section{Methods}

\section{Participants}

This prospective cohort study was conducted during the 2014-2015 minor league hockey season. Participants were recruited from two male AAA Bantam and two male AAA Midget hockey teams in the St. John's metropolitan area.

\section{Intervention}

Preliminary informational sessions, which were meant to brief parents and coaches on the educational program and obtain informed consent, took place prior to the start of the hockey season.

At the beginning of the season, athletes from each team were given a 30-minute Concussion- $U$ educational presentation that focused on concussion recognition, concussion management and return-to-play guidelines. Information provided was based on materials from Parachute Canada. The presentation was carefully designed to engage the audience. It was comprised of PowerPoint slides, videos, review questions and a personal testimonial. A former university hockey player who had retired from the sport because of repeated concussions delivered all four presentations.

\section{Outcomes}

The primary outcome variables were the participants' knowledge of and attitudes about concussion. These were assessed using a modified version of the Rosenbaum Concussion Knowledge and Attitudes Survey-Student Version (RoCKAS-ST). ${ }^{16}$ Two changes were made to the original survey. The first was the removal of question 17 from section 1 . This question was removed because of discomfort surrounding the use of the term "coma," and the authors felt that discussion of this topic was outside the scope of the presentation. The second modification was the addition of a point for "difficulty speaking" in section 5 of the survey. This point was added because one of the signs of a concussion highlighted in Parachute's Smart Hockey Concussion Kit was "slurred speech." ${ }^{17}$ Minimum scores were 0\% and maximum scores $100 \%$. RoCKAS-ST surveys were administered to each participant immediately before and after the presentation to determine individual concussion knowledge and attitudes. Follow-up sessions took place 4 to 6 months after the initial presentations to evaluate the long-term effects of the intervention on concussion knowledge and attitudes.

\section{Statistical Analysis}

All analyses were performed using the Statistical Package for the Social Sciences (SPSS, v. 17.0; Polar Engineering and Consulting, Chicago). Statistics are presented herein as means \pm standard deviations. Statistical significance was set at value of $p<0.05$.

Participants' Concussion Knowledge Index (CKI) and Concussion Attitude Index (CAI) scores were calculated based on a modified RoCKAS-ST answer key. ${ }^{16}$ These were used as quantitative measures of concussion knowledge and attitudes, respectively. Scores were calculated for the Midget group, the Bantam group, and for both groups combined.

A Kolomogorov-Smirnov test showed significant deviations from normality for several of the variables in both the combined and Bantam groups. Therefore, nonparametric tests were employed for all statistical analyses. Friedman's tests were used to determine the effect of the presentation on CKI and CAI scores at pre-presentation, post-presentation, and follow-up for the combined and Bantam groups. Wilcoxon signed rank post-hoc tests using a Bonferroni correction were used to identify significant interactions.

A one-way ANOVA with repeated measures was employed in order to determine the effect of the presentation on Midget CKI and CAI scores at pre-presentation, post-presentation, and followup. Kruskal-Wallis tests were used to determine between-group (i.e., Bantam and Midget) differences in CKI and CAI scores. If significant main effects were in fact detected, a Bonferroni post-hoc test was utilized to identify significant interactions. 


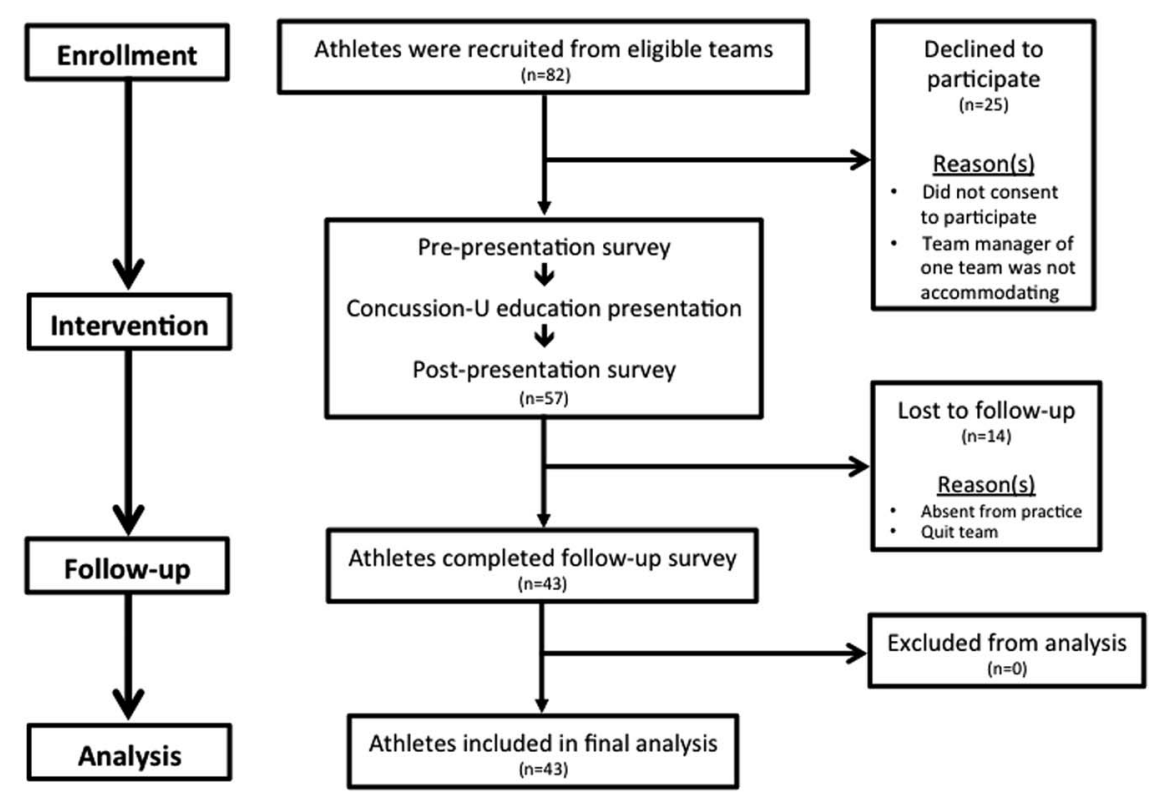

Figure 1: Overview of study design and enrolment

\section{RESULTS}

\section{Study Population}

Of 82 eligible athletes, 57 consented to participate and 43 completed all three surveys. Reasons for dropout were exclusively due to participant absence from follow-up sessions. The enrolment and study designs are shown in Figure 1. Athlete information and estimated concussion incidence are given in Table 1.

\section{Effect of the Presentation on Bantam Group and Midget Group CKI and CAI Scores}

There was a significant $(p<0.001)$ effect of condition on Bantam CKI scores, with scores increasing significantly from preto post-presentation and from pre-presentation to follow-up by $10.73 \%$ (74.58 to $82.58 \%)$ and $7.96 \%$ (74.58 to $80.52 \%)$, respectively $(p<0.001)$. There was also a significant $(p<0.01)$ effect of condition on Bantam CAI scores. Attitude scores increased from pre- to post-presentation by $9.81 \%$ ( 81.08 to $89.03 \% ; p<0.001)$. However, increases from pre-presentation to follow-up did not reach statistical significance (81.75 to $86.45 \%$ ).

There was a significant $(p<0.001)$ effect of condition on Midget CKI scores, which increased by $18.48 \%$ (70.33 to $83.33 \%$ ). Midget CAI scores were not significantly affected by

Table 1: Athlete demographics and concussion incidence among participants

\begin{tabular}{l|c|c|c}
\hline & $\begin{array}{c}\text { Age } \\
\text { (years) }\end{array}$ & Position & $\begin{array}{c}\text { Concussions reported } \\
\text { during season (no.) }\end{array}$ \\
\hline Bantam & $13.71 \pm 0.46$ & $11 \mathrm{D}, 15 \mathrm{~F}, 3 \mathrm{G}, 2 \mathrm{NR}$ & 8 \\
\hline Midget & $15.50 \pm 0.52$ & $4 \mathrm{D}, 7 \mathrm{~F}, 1 \mathrm{G}$ & 7 \\
\hline All & $14.21 \pm 0.94$ & & 15 \\
\hline
\end{tabular}

$\mathrm{D}=$ defence $; \mathrm{F}=$ forward $; \mathrm{G}=$ goalie $\mathrm{NR}=$ position not recorded. condition. There were no significant between-group (Bantam and Midget) differences in CKI or CAI scores at any timepoint. These results are shown in Figures 2 and 3.

\section{Effect of the Presentation on Combined Group CKI and CAI Scores}

The combined group showed a significant $(p<0.001)$ effect of condition on CKI scores, which increased significantly $(p<0.001)$ from pre- to post-presentation and from prepresentation to follow-up by $12.79 \%$ ( 73.40 to $82.79 \%$ ) and $8.49 \%$ (73.40 to $79.63 \%$ ), respectively. There was a significant $(p<0.01)$ effect of condition on combined CAI scores, which increased significantly $(p<0.01)$ from pre- to post-presentation by $8.41 \%$ ( 81.09 to $87.91 \%)$. Increases from pre-presentation to follow-up did not reach statistical significance (81.09 to $83.70 \%$ ). These results are depicted in Figure 4.

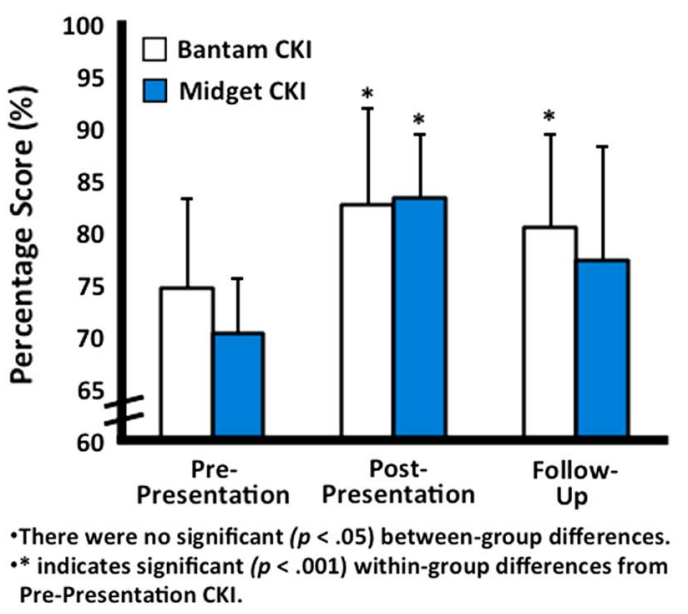

Figure 2: Concussion knowledge changes over time showing no statistically significant inter-group differences 


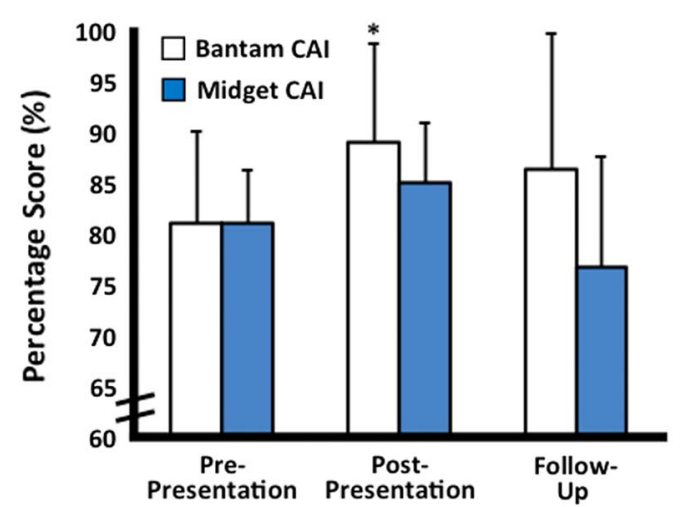

-There were no significant $(p<.05)$ between-group differences. .* indicates significant $(p<.01)$ within-group difference from Pre-Presentation CAI.

Figure 3: Concussion attitude changes over time showing no statistically significant inter-group differences

\section{DiscuSSION}

The results of this study indicate that concussion knowledge and attitudes were significantly improved in male Bantam and Midget AAA hockey players immediately following a Concussion-U educational program. Participants sustained this increase in concussion knowledge from pre-presentation to long-term follow-up; however, the attitude changes did not maintain statistical significance. There were no significant between-group differences at any point in terms of either knowledge or attitudes. These findings demonstrate the program's appropriateness for different age groups and levels of minor league hockey. More importantly, they provide evidence that this Concussion- $U$ program can have a positive long-term impact on concussion knowledge.

Research has shown that concussion education programs may be an effective way to increase concussion knowledge in the short term, ${ }^{11,12,18-22}$ but the studies have failed to demonstrate long-term retention of these gains. Furthermore, some studies ${ }^{23,24}$ reported no significant difference in knowledge levels following provision of concussion education programs. Consequently, there is still some debate regarding the most effective approaches to utilize when educating young athletes about concussion. Many

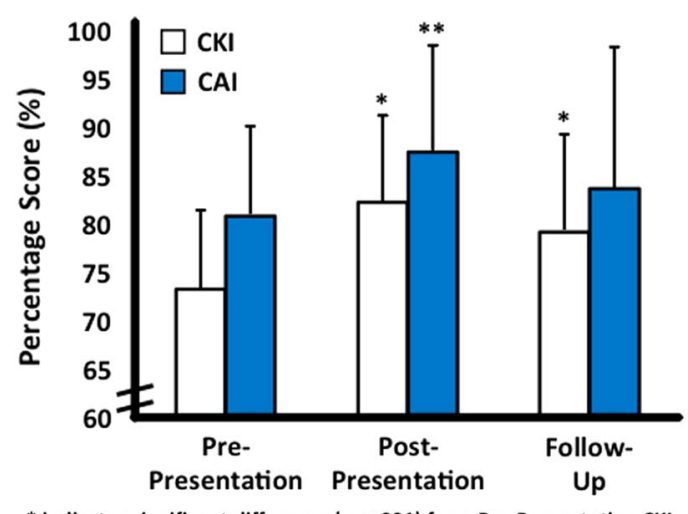

.* indicates significant difference $(p<.001)$ from Pre-Presentation CKI.

-*** indicates significant difference $(p<.001)$ from Pre-Presentation CAI.

Figure 4: Combined group concussion knowledge and attitude changes over time have suggested that the educational programs should be carefully tailored to the audience by accounting for age, sport and social context/environment of the team. It has also been suggested that using a number of educational modalities may increase viewer engagement. ${ }^{9,21,25,26}$ With these recommendations in mind, our group sought to build upon the existing resources from Parachute Canada in designing the Concussion-U educational program. First of all, Concussion-U actively recruited teams for participation, as opposed to relying on coaches and managers to seek out Parachute Canada's resources. Second, face-to-face presentations allowed for a wider variety of educational modalities. The program relied upon the use of PowerPoint slides, videos, participant interaction and personal testimonials. Lastly, a retired hockey player who had left the sport because of repeated concussions delivered the presentation. This was meant to better engage the participants and lend credibility to the program (as they could more easily relate to such a presenter). This approach was supported by a study evaluating the ThinkFirst for Teens injury prevention program, ${ }^{27}$ which suggested that participants are more likely to choose safe behaviours when they have heard from someone who has experienced a traumatic injury.

The significance of the present study is the long-term improvement of concussion knowledge after an education intervention. The failure of previous work to secure adequate long-term data has largely been due to an inability to retain athletes for study completion. ${ }^{21,24} \mathrm{~A}$ factor that likely contributed to improved retention of participants in the present study was involving the coaching staff, parents and players early on in the recruitment process. This provided an excellent route of communication to organize follow-up sessions and minimize participant attrition. In studies that showed no significant improvement after an intervention, recommendations included emphasizing the importance of concussion education to parents, coaches and players; our group sought to address this during the preliminary information sessions. Furthermore, the variety in educational modalities employed may have been an appropriate method for facilitating long-term memory consolidation.

The age of the participants in our study may also have influenced the results. Some authors ${ }^{11,20}$ have shown an increase in knowledge following educational interventions in subjects aged 9-18+ years; however, the studies that failed to demonstrate significant increases were conducted on individuals above the age of 16 years. $^{23,24}$ It is possible that older individuals have more baseline knowledge regarding concussions. As such, they are less likely to show improvement when measuring the effectiveness of an intervention. ${ }^{11}$ Echlin et al. (2014) ${ }^{22}$ previously highlighted this "ceiling effect" in concussion education initiatives. Nonetheless, knowledge scores did not vary significantly between the two age groups in the present study, suggesting that the Concussion-U program is an effective method for increasing concussion knowledge across different levels of youth sport.

Another factor that has been shown to affect baseline concussion knowledge is gender. One study from Kurowski et al. $(2014)^{28}$ reported that female athletes were more knowledgeable about concussion and had better symptom reporting practices than their male counterparts. Because the present study assessed only males, it is possible that we may have overestimated the effectiveness of the presentation (as baseline knowledge levels may have been lower in this group). It would be reasonable to perform an analogous study in female athletes to see if similar changes are observed. 
One of the aims when educating athletes about concussion is to improve the proportion who accurately report their symptoms, yet the link between concussion knowledge and symptom reporting remains unclear. Recent studies ${ }^{12.13}$ have found that an athlete's intention to report symptoms is a better indicator of positive reporting behaviour than their concussion knowledge. Along these lines, new research ${ }^{14}$ has suggested using psychological models, such as the TPB and IBM, to predict the reporting practices of athletes. The TPB posits that athletes' attitudes, subjective norms and perceived behavioural control all influence their intention to report concussion symptoms. ${ }^{14,29}$ The IBM outlines other external factors that may affect reporting behaviour. It claims that environmental constraints, the attitudes of coaches, the competitiveness of the individual, and the importance placed upon the game in question can all affect an athlete's willingness to report concussion symptoms. ${ }^{13,14}$ It stands to reason that many of the above variables are influenced by the collective attitudes of all participants, coaches and parents. This again emphasizes the need to deliver concussion education not only to athletes but also to everyone involved in a given sport.

It is interesting that the initial improvement in concussion attitudes among participants was not maintained at long-term follow-up but that the change in concussion knowledge was. CAI scores were based on athletes' views about returning to play while experiencing symptoms of a concussion, the need to report concussions, whether they feel coaches should keep concussed players on the sidelines, and whether the magnitude of a game should impact an athlete's decision to return while concussed. It is plausible that athletes' attitudes on concussion, more so than their knowledge, are open to influence by the subjective norms of a hockey team. Should this be the case, once athletes are removed from the influence of the Concussion- $U$ program, their attitudes about concussion are liable to revert to their pre-presentation state. Unfortunately, measurement of such dynamics was outside the scope of the present study. Further investigation into the relationship between these factors and their effects on athletes' reporting behaviour is warranted.

The possible limitations of our study include its relatively small sample size, the inability to strictly regulate the date of the long-term follow-up sessions (the researchers had to adhere to dates set by the coaching staffs of the participating teams), the testing environment (after practice in a group setting, which may have affected athlete concentration), and the lack of a control group (control groups have been deemed to be unethical, as previous studies have shown the possible benefits of the intervention).

Future studies in this area should attempt to investigate whether improved concussion knowledge and attitudes have an effect on the incidence of concussions or symptom reporting. They should also investigate how to better affect long-term attitudes about concussion, and whether the results vary for different sports, age groups, genders and geographical locations. Lastly, programs should assess whether including parents and coaches as participants in educational interventions has an effect on long-term results.

\section{Conclusion}

A Concussion- $U$ educational program delivered to elite Bantam and Midget AAA hockey players improved athletes' knowledge of concussion in both the short and long terms.
Attitudes toward concussion were significantly increased immediately following the presentation, but statistical significance was lost at long-term follow-up. Similar programs could be used to enhance concussion knowledge in at-risk athletes.

\section{Disclosures}

Matthew E. Eagles, David J. Bradbury-Squires, Maria F. Powell, Justin R. Murphy, Graeme D. Campbell and Falah B. Maroun hereby declare that they have nothing to disclose.

\section{ACKNOWLEDGMENTS}

The authors would like to acknowledge the contributions of the following individuals and groups: Parachute Canada, for providing materials used in the presentation; Shane Stratton, for providing statistical guidance; and Stephanie Adams, for providing helpful feedback on our paper.

\section{REFERENCES}

1. McCrory P, Davis G, Makdissi M. Second impact syndrome or cerebral swelling after sporting head injury. Curr Sports Med Rep. 2012;11(1):21-3.

2. Weinstein E, Turner M, Kuzma BB, Feuer H. Second impact syndrome in football: new imaging and insights into a rare and devastating condition. J Neurosurg Pediatr. 2013;11(3):331-4.

3. McNaughton-Filion L. Inquest into the death of Rowan Stringer. Verdict of the coroner's jury. Office of the Chief Coroner, Province of Ontario; 2015. Available from: http://www.mcscs.jus. gov.on.ca/sites/default/files/content/mcscs/docs/ec168381.pdf.

4. McCrory P, Zazryn T, Cameron P. The evidence for chronic traumatic encephalopathy in boxing. Sports Med. 2007;37(6):467-76.

5. McKee AC, Cantu RC, Nowinski CJ, Hedley-Whyte ET, Gavett BE, Budson AE, et al. Chronic traumatic encephalopathy in athletes: progressive tauopathy after repetitive head injury. J Neuropathol Exp Neurol. 2009;68(7):709-35.

6. Mez J, Stern RA, McKee AC. Chronic traumatic encephalopathy: where are we and where are we going? Curr Neurol Neurosci Rep. 2013;13(12):407.

7. Echlin PS, Tator CH, Cusimano MD, Cantu RC, Taunton JE, Upshur RE, et al. A prospective study of physician-observed concussions during junior ice hockey: implications for incidence rates. Neurosurg Focus. 2010;29(5):E4.

8. Daneshvar DH, Nowinski CJ, McKee AC, Cantu RC. The epidemiology of sport-related concussion. Clin Sports Med. 2011; 30(1):1-17, vii.

9. Harmon KG, Drezner J, Gammons M, Guskiewicz K, Halstead M, Herring $S$, et al. American medical society for sports medicine position statement: concussion in sport. Clin J Sport Med. 2013;23(1):1-18

10. McCrory P, Meeuwisse WH, Aubry M, Cantu B, Dvorák J, Echemendia RJ, et al. Consensus statement on concussion in sport: the 4th International Conference on Concussion in Sport held in Zurich, November 2012. Br J Sports Med. 2013;47(5):250-8.

11. Bagley AF, Daneshvar DH, Schanker BD, Zurakowski D, d'Hemecourt CA, Nowinski CJ, et al. Effectiveness of the SLICE program for youth concussion education. Clin J Sport Med. 2012; 22(5):385-9.

12. Bramley H, Patrick K, Lehman E, Silvis M. High school soccer players with concussion education are more likely to notify their coach of a suspected concussion. Clin Pediatr (Phila). 2012; 51(4):332-6.

13. Kroshus E, Baugh CM, Daneshvar DH, Nowinski CJ, Cantu RC. Concussion reporting intention: a valuable metric for predicting reporting behavior and evaluating concussion education. Clin $\mathbf{J}$ Sport Med. 2015;25(3):243-7.

14. Kroshus E, Baugh CM, Daneshvar DH, Viswanath K. Understanding concussion reporting using a model based on the theory of planned behavior. J Adolesc Health. 2014;54(3):269-74. 
15. Caron JG, Bloom GA, Falcao WR, Sweet SN. An examination of concussion education programmes: a scoping review methodology. Inj Prev. 2015;21(5):301-8. Epub ahead of print Mar 30.

16. Rosenbaum AM, Arnett PA. The development of a survey to examine knowledge about and attitudes toward concussion in high-school students. J Clin Exp Neuropsychol. 2010;32(1): 44-55.

17. Parachute Canada Smart Hockey Concussion Kit; 2015. Available from: http://www.parachutecanada.org/downloads/programs/Smart HockeyConcussionKit_FINAL2_11FE15.pdf.

18. Cook DJ, Cusimano MD, Tator CH, Chipman ML. Evaluation of the ThinkFirst Canada smart hockey, brain and spinal cord injury prevention video. Inj Prev. 2003;9(4):361-6.

19. Goodman D, Bradley NL, Paras B, Williamson IJ, Bizzochi J. Video gaming promotes concussion knowledge acquisition in youth hockey players. J Adolesc. 2006;29(3):351-60.

20. Miyashita TL, Timpson WM, Frye MA, Gloeckner GW. The impact of an educational intervention on college athletes' knowledge of concussions. Clin J Sport Med. 2013;23(5):349-53.

21. Cusimano MD, Chipman M, Donnelly $\mathrm{P}$, Hutchison MG. Effectiveness of an educational video on concussion knowledge in minor league hockey players: a cluster randomised controlled trial. Br J Sports Med. 2014;48(2):141-6.

22. Echlin PS, Johnson AM, Holmes JD, Tichenoff A, Gray S, Gatavackas H, et al. The Sport Concussion Education Project.
A brief report on an educational initiative: from concept to curriculum. J Neurosurg. 2014;121(6):1331-6.

23. Kroshus E, Daneshvar DH, Baugh CM, Nowinski CJ, Cantu RC. NCAA concussion education in ice hockey: an ineffective mandate. Br J Sports Med. 2014;48(2):135-40; Epub ahead of print Aug 16, 2013.

24. Echlin PS, Johnson AM, Riverin S, Tator CH, Cantu RC, Cusimano $\mathrm{MD}$, et al. A prospective study of concussion education in 2 junior ice hockey teams: implications for sports concussion education. Neurosurg Focus. 2010;29(5):E6.

25. Ginns P. Meta-analysis of the modality effect. Learn Instruct. 2005;15(4):313-31.

26. Provvidenza CF, Johnston KM. Knowledge transfer principles as applied to sport concussion education. Br J Sports Med. 2009;43 (Suppl 1):i68-75.

27. Gerhardstein D. ThinkFirst for teens injury prevention program. Evidence-based practice: are we making a difference? SCI Nurs. 2007;24(3). Available from: http://www.parachutecanada. org/downloads/research/evaluation/ThinkFirstForTeens-InjuryPrevention-Program.pdf.

28. Kurowski B, Pomerantz WJ, Schaiper C, Gittelman MA. Factors that influence concussion knowledge and self-reported attitudes in high school athletes. J Trauma Acute Care Surg. 2014;77(3 Suppl 1): S12-7.

29. Chrisman SP, Quitiquit C, Rivara FP. Qualitative study of barriers to concussive symptom reporting in high school athletics. J Adolesc Health. 2013;52(3):330-5. 